\title{
Mundo da Vida, Ethos Democrático e Mundialização: A Democracia Deliberativa segundo Habermas
}

Nythamar de Oliveira

PUCRS/CNPq

nythamar@yahoo.com

resumo 0 artigo procura mostrar em que sentido a democracia deliberativa proposta pela teoria discursiva de Jürgen Habermas dá conta do problema dos reducionismos econômicos e juridificantes da mundialização ou globalização, entendida como uma colonização técnico-sistêmica do mundo da vida. Recorrendo a sua concepção de um ethos democrático transnacional embasado na soberania popular, a teoria habermasiana logra resgatar 0 caráter normativo da mundialização através da irredutibilidade de valores humanos como a liberdade, a dignidade e os direitos humanos, inerentes às mais diferentes e incompatíveis autocompreensões de mundos da vida.

palavras-chave democracia deliberativa; ethos democrático; juridificação; mundialização; mundo da vida; soberania popular

1. Segundo Norberto Bobbio, podemos estudar a gênese do Estado moderno em termos de sua constitucionalidade e soberania nacional, conforme modelos mais ou menos liberais, sociais ou democráticos (BOBBIO, 2000). De uma maneira geral, estudiosos do Direito tendem a enfatizar apenas uma dessas correntes de forma a contrapor um modelo de democracia liberal, por exemplo, a modelos de democracia social e de um Estado democrático de direito. A questão da soberania nacional deveria, segundo tal divisão de trabalho, ser tratada em termos constitucionais, pela separação e correlação dos três poderes, delimitando as esferas de ação e atribuições de instituições e cidadãos, como num jogo interativo de direitos e deveres. Assim, o modelo contratualista serviria para embasar 
a legitimação política em pleno acordo com o consentimento moral da sociedade civil, na medida em que o indivíduo, a sociedade e o Estado se mantêm numa relação estável de equilíbrio. Contrastando com as diferentes propostas de autores contratualistas como Hobbes, Locke, Rousseau e Kant, os modelos sociais ou comunitaristas de pensadores como Hegel, Marx e Gramsci recorrem a argumentos metafisicos, historicistas ou dialéticos para dar conta do mesmo problema, pressupondo uma unidade sistêmica ou orgânica entre Estado, razão e historicidade. Para além das simplificações características de modelos jusnaturalistas e positivistas, John Rawls e Jürgen Habermas mostraram que as relações entre moral, direito e política não somente se tornaram problemáticas proporcionalmente às diferenciações cada vez mais complexas entre os níveis jurídicos, políticos e econômicos das instituições sociais, mas que a própria concepção de um Estado democrático de direito carece de legitimação satisfatória em seus fundamentos constitucionais. Tanto Rawls quanto Habermas recorrem a argumentos recursivos ou reflexivos numa tentativa radical de romper, por um lado, com o "fato da razão" kantiano de uma fundamentação moral do direito e do político, e por outro lado, com o historicismo e o positivismo decorrentes de leituras neo-hegelianas e neo-marxistas (RAWLS, 1996; HABERMAS, 1999). A idéia de um equilíbrio reflexivo (reflective equilibrium) a partir do qual poderíamos explicitar os checks and balances de um Estado constitucional de direito ("Sistema de Freios e Contrapesos") resolveria de modo deveras convincente os desafios da normatividade prática entre a faticidade das intuições cotidianas de valores morais e a abstração dos ideais de liberdade, igualdade e justiça que se retro-alimentam nos dois sentidos de calibragem entre pessoas e instituições, garantindo um controle de constitucionalidade pela deliberação reflexiva entre os três poderes. O termo "pessoa" deve ser entendido aqui em um sentido pós-metafísico, enquanto correlato ao indivíduo humano e cidadão (homme et citoyen), sem pressupostos ontológicos ou subjetivos. Com efeito, uma transformação semântica da concepção kantiana de subjetividade transcendental, em particular do seu ideal de personalidade (Persönlichkeit, Personalität), subjaz à concepção normativa de pessoa para viabilizar o dispositivo procedimental do equilíbrio reflexivo, juntamente com os dispositivos hipotéticos da "posição original" e da "sociedade bem ordenada", de forma a responder a críticas 
comunitaristas em defesa do individualismo metodológico inerente ao liberalismo político, concebido não mais como uma doutrina abrangente de autocompreensão (self-understanding, comprehensive doctrine), mas como um construtivismo, num modelo coerentista de justificativa epistêmicomoral (OLIVEIRA, 2007). Destarte, o que Rawls chama de concepção normativa de pessoa, correlata a uma teoria ideal e a uma teoria não-ideal de justiça como eqüidade (justice as fairness), traduz o mesmo modelo reflexivo de democracia que encontramos na articulação habermasiana entre sistema (System) e mundo da vida (Lebenswelt) (BAYNES, 1992). Numa pesquisa sobre o que seria uma fenomenologia da justiça, tenho procurado aproximar as concepções de equilíbrio reflexivo e mundo da vida nesses dois autores, de forma a investigar os aportes normativos de uma hermenêutica da cultura política democrática, capaz de integrar aspectos semânticos e epistêmico-morais aos desafios empíricos e históricos da ética aplicada, notadamente em estudos sobre os direitos humanos (OLIVEIRA, 2006, 2008). No presente artigo, limitar-me-ei a revisitar o conceito de democracia deliberativa que Habermas retoma de Rawls, numa tentativa de rever o problema da juridificação (Verrechtlichung), para além de sua original acepção pejorativa, aliada a reducionismos econômicos, financeiros e administrativos, tais como os encontramos numa globalização econômica neoliberal, entendida como uma colonização técnicosistêmica do mundo da vida. Embora não possa examinar todos os desdobramentos e implicações de tal concepção de juridificação para os direitos humanos, creio ser possível evitar as distorções e patologias sociais que solapariam um genuíno reconhecimento da liberdade humana, reificada através de relações juridicamente determinadas, reduzindo o indivíduo a uma mera "pessoa de direito", num processo colonizador de globalização que desacreditaria a própria idéia emancipadora da democratização (FLICKINGER, 2006; HONNETH, 2007). Recorrendo a uma concepção de ethos democrático transnacional embasado na soberania popular, a teoria habermasiana logra resgatar o caráter normativo da mundialização através da irredutibilidade de valores da pessoa, tais como a liberdade, a dignidade e os direitos humanos, inerentes às mais diferentes e incompatíveis formas de autocompreensão (Selbstverständnis) de mundos da vida. Creio ser possível resgatar, outrossim, uma concepção normativa de reconhecimento intersubjetivo inerente às estruturas 
comunicativo-performativas de nossas relações, vivências e práticas cotidianas, tanto em termos fáticos de aceitação social (soziale Geltung) do outro quanto em termos contrafáticos de validade (Gültigkeit) ideal (HABERMAS, 1998, p. 4).

2. A teoria habermasiana do agir comunicativo, e particularmente a sua teoria discursiva da democracia, tem sido caracterizada como uma fenomenologia social do mundo da vida (WELTON, 2000; STEINBOCK, 1996). Ademais, importantes obras de reconstrução do pensamento de Habermas deixam transparecer a unidade de seu pensamento ético-político em termos sociológicos e filosóficos segundo uma vertente hermenêutica (HORSTER, 2001; PINZANI, 2008). Se quisermos explicitar o que seria propriamente, segundo Habermas, uma hermenêutica de autocompreensão (Selbstverstehen) entre atores sociais que resistem a imperativos sistêmicos e a diferentes formas mais ou menos sutis de colonização subsistêmica de vários níveis de reprodução social do mundo da vida, poderíamos explorar, com efeito, o papel da mídia e dos formadores de opinião pública, programas político-partidários em época de eleições, o chamado tráfico de influência das bancadas ou lobbies políticos e muitas outras formas de interação entre níveis diferenciados da esfera pública (Öffentlichkeit) que nos remetem à razão comunicativa que constitui o tecido próprio de tais mundos da vida. Trata-se, portanto, de investigar em que medida o mundo da vida que viabiliza pelo agir comunicativo a idéia habermasiana de democracia deliberativa nos remete a uma normatividade prática que não se deixe reduzir a uma outra variante da tecnologia política ou da engenharia social nem a uma reflexividade transcendental do tipo kantiana ou rawlsiana, por exemplo, na concepção normativa de pessoa. O procedimentalismo kantiano correlato ao ethos democrático da soberania popular (Volkssouveränität) é invocado por Habermas não apenas para caracterizar um modelo radical de democracia deliberativa em nível doméstico do Estado liberal, mas ainda em um nível transnacional, sobretudo à luz do fenômeno da mundialização, entendido como um cosmopolitismo do tipo republicano capaz de resistir a uma globalização econômico-financeira, neoliberal ou corporativa. Assim como eminentes economistas nos alertam para os perigos de uma globalização unilateral- 
mente guiada por interesses geopolíticos e econômicos - sobretudo de grandes multinacionais e complexos tecnoburocráticos dos mais ricos e poderosos do planeta -, o papel democratizante de uma mundialização solidária e anti-instrumentalizadora em Habermas vem corroborar o seu ideal cosmopolita de justiça global (STIGLITZ, 2002). Tal concepção de mundialização democratizante nos remete, em última análise, a uma transformação estrutural das relações internacionais em direção a uma constelação pós-nacional (postnationale Konstellation) que subscreva ao ethos democrático de consulta popular decente, a procedimentos participativodeliberativos e ao reconhecimento recíproco entre as partes envolvidas (HABERMAS, 2001; ROSENAU, 2002). Embora Habermas rejeite a fundamentação pragmático-transcendental da ética do discurso de Apel e proclame a destranscendentalização (Detranszendentalisierung) da subjetividade através de uma pragmática formal (Formalpragmatik), creio ser possível argumentar que a sua concepção de Lebenswelt permanece devedora de uma fenomenologia hermenêutica e que poderia ser ainda caracterizada em termos semânticos transcendentais (HABERMAS, 1998, p. 524). Penso aqui na caracterização do "transcendental" na teoria apeliana da linguagem, tal como a formulou Herrero em seus termos próprios termos auto-reflexivos, a saber, "a descoberta de que essas condições são transcendentais nos mostra que elas não poderão ser negadas sem caírem em contradição performativa, porque elas estarão necessariamente presentes em qualquer tentativa de negá-las como condição transcendental do sentido dessa negação" (HERRERO, 2000, pp. 169-170). Outrossim, uma fenomenologia da justiça opera, com efeito, uma transformação hermenêutica da chamada "interpretação kantiana" do equilíbrio reflexivo de Rawls. Se, por um lado, Habermas quer evitar uma redução dos agentes morais e atores sociais a meros clientes de um sistema reificante de mundos sociais, por outro lado, ele também procura evitar as aporias kantianas de concepções normativas como a do equilíbrio reflexivo rawlsiano. Ademais, as formas comunicativas desempenham, para Habermas, um papel catalisador e revitalizante da própria concepção fenomenológico-hermenêutica de mundo da vida. Como não há socialização humana sem razão e agir comunicativos, na medida em que estes constituem o próprio meio (medium) para a reprodução de mundos da vida (HABERMAS 1989, p. 224), a interação orgânica entre consenso normativo e 


\section{4}

sistema institucional inerente a processos decisórios de uma democracia deliberativa nos remete desde sempre a uma correlação entre linguagem, ontologia e intersubjetividade. O próprio Habermas viu na sua guinada lingüístico-pragmática a emergência de um novo paradigma alternativo aos paradigmas ontológico e epistemológico que caracterizaram, respectivamente, as abordagens pré-modernas (teorias políticas clássicas) e modernas (filosofias da consciência) da filosofia prática. Assim como Heidegger e Foucault, Habermas buscou incessantemente uma terceira via capaz de evitar as reduções racionalistas e empiristas a diferentes versões de dualismo, monismo ou ceticismo (HABERMAS, 1987b). A fim de não incorrer em historicismo transcendental, niilismo ou relativismo, Habermas acaba recorrendo a uma argumentação "quase-transcendental” que, segundo ele, evita as aporias de uma antropologia filosófica e de uma filosofia da história (inevitáveis em modelos liberais kantianos e comunitaristas hegelianos, respectivamente). É tal postura que denomino, provisoriamente e faute de mieux, de "perspectivismo semântico-transcendental" para caracterizar a sua pragmática formal, supostamente não-transcendental, negando um sentido robusto de fundamentação última à la Apel ou de "fato da razão" kantiano. Seguindo uma intuição de Hans Joas em sua resenha da coletânea de Habermas Zwischen Naturalismus und Religion ("Die Religion der Moderne", Die Zeit 13.10.2005), creio que todo o seu projeto pós-metafísico tenta dar conta da normatividade correlata aos horizontes do observador e do agente moral ou ator social, desde as investigações seminais sobre a lógica das pesquisas sociais no final dos anos 60 (Zur Logik der Sozialwissenschaften) até as suas formulações de teorias discursivas da democracia e do direito nos anos 90. Segundo tal "dualismo de perspectivas", Habermas logra destarte integrar os últimos resultados de pesquisas empíricas do naturalismo (em biogenética, neurociências, inteligência artificial, ciências cognitivas, biologia molecular) aos legados filosóficos e culturais tradicionalmente associados a reflexões sobre a normatividade inerente a relações intersubjetivas do mundo da vida (HABERMAS, 2008).

3. De acordo com Habermas, a questão da normatividade moral (formulada pela ética do discurso) deve ser articulada com a questão social e 
política da institucionalização de formas de vida, na própria concepção de um modelo integrado diferenciando o mundo sistêmico das instituições (definido pela capacidade de responder a exigências funcionais do meio social) do mundo da vida (isto é, das formas de reprodução cultural, societária e pessoal que são integradas através de normas consensualmente aceitas por todos os participantes) (HABERMAS, 1987a, pp. 113152). A grande questão que motiva tal modelo dual da sociedade é, para Habermas, a de dar conta dos complexos processos de reprodução social - material e simbólica - em seus diversos níveis de integração social, reprodução cultural e socialização interpessoal em face de mecanismos estruturais de controle - notadamente, poder e dinheiro -, tais como os encontramos hoje na chamada globalização dos mercados econômicos e financeiros (HABERMAS, 1984, p. 107). Habermas procura, ao mesmo tempo, evitar um determinismo econômico (da Überbau pela Unterbau, na terminologia marxista) e acatar as contribuições sociológicas (em particular, de Weber, Durkheim e Parsons) para uma compreensão dos processos de diferenciação social, cultural e política, sem incorrer em formas sutis de funcionalismo. Assim, Habermas procura mostrar como o mundo da vida pode preservar um princípio de autonomia num nível público de normatividade e universalizabilidade, justificando a integração e diferenciação de instituições tais como a família, a sociedade civil, o estado e organizações governamentais e não-governamentais, com relação aos subsistemas econômicos, políticos e administrativos (HABERMAS, 1984; 1987a). Assim, a faticidade do mundo da vida, em particular, expressa numa cultura política democrática pluralista, deve ser compreendida de maneira correlata à normatividade e validade da autonomia pública, de forma a superar a atual crise paradigmática da democracia, especialmente a crise de legitimação que caracteriza o Estado moderno, sem incorrer nas aporias de uma crítica da ideologia ou diferentes versões de relativismo, ceticismo e historicismo em filosofia política. Pelo seu procedimentalismo kantiano, a concepção habermasiana de democracia participativodeliberativa se propõe como uma alternativa aos modelos liberais (especialmente, Rawls) e comunitaristas (neo-aristotélicos, neohegelianos, neo-marxistas). A fim de evitar a auto-referencialidade da razão prática kantiana, Habermas reconcebe a "autonomia pública" como a disponibilidade de uma rede diferenciada de arranjos comunicativos 
para a formação discursiva da vontade e opinião pública, na medida em que um sistema de direitos individuais básicos fornece exatamente as condições para que as formas de comunicação necessárias para uma constituição do direito politicamente autônoma sejam assim institucionalizadas. No entanto, apesar de sua construção intersubjetiva do mundo social, uma teoria crítica discursiva poderia incorrer em generalizações de concepções empíricas de subjetividade, sobretudo na formulação de uma identidade coletiva, na própria autocompreensão de cultura em suas dimensões estética, moral e política. As idéias correlatas de democratização e de uma mundialização multicultural e transnacional, para além de uma globalização econômica neoliberal, podem contribuir, em seu próprio intento hermenêutico reflexivo, para uma normatividade aberta e anti-sistêmica. Segundo Habermas, os fundamentos necessários para uma autodeterminação capaz de realizar o projeto modernista de emancipação, embasado na razão e ação comunicativas, devem integrar a vida social cotidiana e exigem, portanto, um engajamento da sociedade civil, através da participação política, associações voluntárias, movimentos sociais e desobediência civil, no processo de busca de entendimento mútuo (Verständigung) em juízos de validade. É precisamente neste rapprochement crítico entre um nível comunicativo-discursivo e um nível sociopolítico da ação coordenada - níveis inseparáveis da vida prática intersubjetiva - que Habermas logra efetivar uma verdadeira guinada lingüístico-pragmática em filosofia política.

4. Ao cotejarmos o sétimo capítulo de Faktizität und Geltung de Habermas (1998) e o texto seminal de Rawls sobre a idéia de razão pública em The Law of Peoples (1999), podemos inferir que tanto Habermas quanto Rawls contribuem de maneira decisiva para corroborar uma teoria deliberativa da democracia capaz de responder aos desafios sistêmicos de instituições políticas, econômicas e jurídicas, por exemplo, cada vez mais acentuados com uma globalização irreversível e agora até mesmo compatibilizada com a democratização de sociedades tão diferentes como a brasileira, a chinesa, a indiana e a russa. Assim como a democracia, no sentido clássico original, poderia ser entendida como uma forma de existência social ou enquanto fenômeno político com seus diferenciados 
mundos da vida oriundos de uma civilização como a grega, a globalização ou mundialização poderia igualmente ser entendida à luz da modernização e racionalização inerentes a mundos da vida e seus processos de civilização ocidental, como já o mostraram Braudel (1949), Wallerstein (1979) e Held (1995). Tanto Rawls quanto Habermas partem de pressupostos pragmáticos quanto à solidificação da democracia e processos de democratização em sociedades ocidentais: depois de vários séculos de conflitos e lutas pelo reconhecimento através de imperialismos e colonialismos, o mundo pós-guerra pode finalmente contemplar a possibilidade de uma coexistência pacífica na proporção em que um número cada vez maior de nações adere às regras do jogo democrático. Em ambos autores, a idéia de recursividade ou reflexividade é decisiva para entendermos o tipo de democracia deliberativa a ser diferenciada de outras formas de democracia - direta, representativa, liberal, republicana - como as conhecemos através de mais de 2500 anos de história. Como bem observou John Dryzek, temos assistido a uma verdadeira "guinada deliberativa" nas democracias liberais da última década do segundo milênio (DRYZEK, 2000, p. 55). Cada vez mais, trata-se agora de entender a legitimidade pelo procedimento de processos deliberativos envolvendo uma participação sempre mais inclusiva e diversificada de atores nos processos decisórios - não apenas pelo voto, direitos constitucionais ou procedimentos já estabelecidos e previstos em codificações jurídicas (FISHKIN, 1991). Pela deliberação, a própria concepção de ação comunicativa é alargada e sempre passível de ser revisitada, inovada, ratificada e retificada. O papel mesmo de manipulação pela mídia e por grupos sociais com interesses bem definidos também volta a ser revisitado, na medida em que a deliberação se mantém concomitantemente em equilíbrio reflexivo amplo e restrito, ou seja, não apenas para traduzir preferências pessoais e identitárias, mas também nas concepções bem mais complexas e a longo prazo, como valores e juízos morais, religiosos e históricos que determinam nossos horizontes de autocompreensão. Como não recorre a uma articulação contratualista ou procedimentalista do tipo rawlsiano (dispositivos procedimentais de representação), Habermas decerto evita um nível abstrato, solipsista e a-histórico do experimento do pensamento (thought experiment) - que poderia, segundo seu intento, ser qualificado de "transcendental", da teoria ideal. Por outro lado, não é possível 
tampouco tomar a realidade do mundo social como um dado, como se o empiricamente mensurável em relações e estruturas do comportamento e da vida social fosse capaz de justificar em termos racionais uma normatividade, objetivamente estabelecida, como fazem todos os adeptos do naturalismo e do positivismo sociológico. Esta crítica Habermas pode aplicar tanto a positivistas quanto a comunitaristas (da Sittlichkeit hegeliana) e pensadores sistêmicos (notadamente, Niklas Luhmann). Assim como Rawls e Luhmann, Habermas visa diferentes níveis de articulação entre ética e filosofia política em sua teoria interdisciplinar da democracia, lidando com questões de teoria política, epistemologia moral, economia política, teoria da linguagem, sociologia do direito e psicologia social. Trata-se, portanto, de uma interlocução profícua com diversos autores e correntes da teoria da democracia, em filosofia política e nas ciências sociais, comportamentais e jurídicas. O seu pensamento político-filosófico em torno dos desafios normativos da mundialização pretende, em suma, argumentar por uma defesa racional da democracia deliberativa na medida em que logra resgatar as dimensões cidadãs da participação e da solidariedade, excluídas pela secularização de credos e cosmovisões religiosas, supostamente ausentes do modelo rawlsiano. Creio que podemos destacar três grandes problemas que permeiam, grosso modo, sua teoria da democracia deliberativa, sobretudo no desenvolvimento das teses centrais de sua mais importante obra depois da Theorie der kommunikativen Handelns, Faktizität und Geltung (1992), a saber:

1. O problema do procedimentalismo e da neutralidade numa teoria do direito e da democracia;

2. O problema do universalismo, em contraposição a modelos comunitaristas e particularistas e, no que eu considero uma "crítica imanente" ao universalismo rawlsiano (em particular, ao seu procedimentalismo puro);

3. O problema do igualitarismo, em contraposição ao individualismo possessivo, e no caso de Habermas, como alternativa a modelos solipsistas e monológicos das filosofias da consciência ou filosofias do sujeito. A questão do outro concreto, da alteridade do outro e do seu reconhecimento, desenvolvida em escritos mais recentes, atestam a importância do desafio pós-moderno, para além das críticas desenvolvidas em defesa da modernidade iluminista. Assinalo, en passant, que considero O Discurso Filosófico da Modernidade um texto não apenas problemático (do ponto de 
vista de suas leituras de grandes pensadores como Nietzsche, Heidegger e Foucault), mas que pode suscitar uma leitura, a meu ver, errônea, do projeto habermasiano como um todo. Por exemplo, pensando em críticas como a de Dominique Janicaud, de que "Habermas n'avais pas compris Nietzsche", podemos pôr tudo a perder com relação a leituras que Habermas nos oferece de outros pensadores políticos, tais como Arendt, Castoriadis e Rawls (HABERMAS, 1987b).

Podemos situar no primeiro problema todas as questões referentes aos modelos de justificação da ética em geral, como por exemplo, de modelos deontológicos, em contraposição a modelos teleológicos, eudaimonistas e utilitaristas (HABERMAS, 1989, pp. 4-19). Habermas concorda com Paul Ricoeur, quando este observa que a distinção entre uma meta-ética (formal, procedimental) e uma ética normativa (substantiva) permanece tão problemática quanto arbitrária, a menos que visemos a uma ética aplicada (concreta), capaz de assegurar a articulação normativa entre justificativa e aplicabilidade (RICOEUR, 1992). Assim como Rawls e Ricoeur, Habermas recorre a uma versão pós-hegeliana do procedimentalismo kantiano, com a pretensão de contemplar todas as reivindicações de modelos já desenvolvidos, de forma a dar conta da oposição espectral entre egoísmo e altruísmo (tematizadas pelas perspectivas do participante e do observador, da primeira e da terceira pessoas), e da tensão irresolúvel entre uma abordagem abstrata da moral e uma concepção concreta do ethos democrático. Com efeito, a dimensão deontológica do procedimentalismo nos remete ao problema da neutralidade, evidenciado no debate entre Rawls e Habermas (HABERMAS, 1998, p. 56-66). Tal movimento na direção do abstrato para o concreto (vom Abstrakten zum Konkreten), segundo Habermas, significa que o grau de concreção a ser alcançado será tanto maior quanto mais internalizada pelo sistema for a perspectiva de tal apresentação, inicialmente externa: os direitos com que os cidadãos devem se reconhecer mutuamente na medida em que regulam legitimamente formas compartilhadas do mundo da vida - o que se dá, inevitavelmente, por meio do Direito positivo (HABERMAS, 1998, p.135-151).

Em segundo lugar, temos a questão de contrapor um universalismo de inspiração kantiana a um comunitarismo de inspiração hegeliana. O comunitarismo abrange críticos de Rawls tão diversos quanto Alasdair 
MacIntyre, Charles Taylor, Michael Sandel e Michael Walzer. Autores como Amy Gutmann e Will Kymlicka mostraram as limitações de muitas das críticas comunitaristas na medida em que ainda pressupõem valores liberais de modelos universalistas. Habermas argumentou de maneira bastante convincente contra a identificação do comunitarismo com um republicanismo de inspiração rousseauniana (HABERMAS, 1998, p.100103). Feitas tais ressalvas, o comunitarismo pode ser compreendido como uma reformulação teórico-política do ideal republicano da comunidade enquanto fundamento, princípio ou justificativa racional da sociabilidade e da justiça, numa rejeição explícita do ideal de autonomia individual. Assim como o contrato social e o princípio da universalizabilidade servem para fundamentar, balizar ou justificar modelos universalistas liberais (neo-contratualistas), o ideal da comunidade e suas idéias correlatas (tradição, eticidade, língua, história, identidade cultural, étnica e religiosa) são evocados numa argumentação comunitarista recorrendo não mais ao ideal revolucionário marxiano, mas à concepção hegeliana de comunidade (Gemeinde, Gemeinschaft) que permeia todas as relações e instituições sociais, integrando as esferas privadas e pública (família, sociedade civil-burguesa e Estado). Habermas aceita as principais premissas da crítica comunitarista, desde que não incorram em uma falácia naturalista ou no reverso do círculo hermenêutico que caracteriza a nossa impossibilidade de prescindir de pré-compreensões do mundo da vida, como se a eticidade, o ethos social, o modus vivendi ou a socialização pudessem justificar em termos normativos os dados empíricos da vida comum (HABERMAS, 1998, pp. 310-313). Embora o termo "comunidade" não seja ele mesmo inequívoco ou isento de polissemia, podemos aludir a cinco características fundamentais de forma a diferenciar a especificidade teórico-política do comunitarismo:

1.Toda comunidade pressupõe uma idéia de bem comum, seja através de interesses ou fins comuns, seja através de valores ou qualidades comuns, capazes de assegurar a coesão e integração de um grupo social qualquer associações voluntárias, comunidades, estamentos, corporações.

2.Os ideais liberais de liberdade e igualdade implicam uma correlação fundamental com a fraternidade (liberté, égalité, fraternitê) na medida em que a solidariedade e a intersubjetividade são pressupostas no próprio sentido de pertença (appartenance, membership, Mitgliedschaft) inerente a um grupo social. 
3. Seguindo uma crítica famosa de Michael Sandel ao conceito rawlsiano de "eu" (self), para distinguirmos o "eu" de seus fins - que, segundo o modelo deontológico de Rawls, seriam sempre a posteriori, "the self is prior to the ends which are affirmed by it" (RAWLS, 1971, p. 560) -, é inevitável que incorramos em uma das duas situações antitéticas: a de um sujeito radicalmente situado ("a radically situated subject") ou a de um sujeito radicalmente desencarnado ("a radically disembodied subject"). Sandel e MacIntyre argumentam, contra a suposta neutralidade do liberalismo deontológico, que nossa identidade (social, cultural, étnica) é na verdade determinada por fins que não foram escolhidos por indivíduos isolados ou desinteressados, mas descobertos e desvelados pela nossa inserção num determinado contexto social - daí a fórmula lapidar do "embedded self", o eu arraigado, inserido, situado, contra o "unencumbered self" (o eu desimpedido, isolado, segundo uma formulação abstrata) (SANDEL, 1982).

4. Sentimentos morais não podem ser adequadamente expressos em termos individuais, o que inviabilizaria a articulação deontológica entre uma justificação transcendental ou procedimental e uma aplicação moral empírica. Taylor argumenta contra o individualismo metodológico dos modelos contratualistas liberais precisamente pela negligência das práticas e crenças de pano-de-fundo (background beliefs and practices), num nível de normatividade tácita que perpassa os sentimentos morais na vida cotidiana e no senso comum.

5. A mediação se faz necessária para darmos conta das interrelações entre indivíduos e sociedade, da intersubjetividade de toda relação humana e da própria individuação através da socialização. Somente pela eticidade (Sittlichkeit) podemos passar do ideal universalizável de uma moralidade particular à efetiva realização da sociabilidade, unindo direito e moral, ética e política.

Finalmente, no terceiro campo de problemas, temos a questão do igualitarismo, decorrente da própria formulação do princípio de eqüidade (fairness) e do princípio da diferença, não apenas na idéia de igualdade equiitativa de oportunidades mas ainda no primeiro princípio da justiça, da igual liberdade. Se o liberalismo político não pode se sustentar separadamente do igualitarismo e do seu ideal conseqüencialista de "racionalidade deliberativa", termina por articular as liberdades básicas e 
o princípio liberal da tolerância numa versão liberal de republicanismo democrático (vontade geral e igualdade política), o que nos remeteria à concepção habermasiana de soberania popular. Afinal, trata-se aqui de uma teoria da democracia liberal constitucional que visa promover a liberdade igual para todos e a igualdade eqüitativa de oportunidades, na medida em que as desigualdades são aceitáveis para os menos privilegiados. Ao contrário do individualismo possessivo do modelo hobbesiano e das diferentes versões de libertarianismo, a concepção democrático-deliberativa de justiça retoma uma concepção de justiça como imparcialidade e não como decorrente de um regramento entre interesses conflitantes. Nada mais errôneo, portanto, do que aproximar modelos liberais em Rawls e Habermas de uma versão neoliberal ou libertária que defenda um Estado mínimo. Por outro lado, a teoria discursiva da democracia deliberativa não defende tampouco um igualitarismo radical, como em modelos comunitaristas ou ainda em defesa irrestrita do Estado de bemestar. Tal seria a concepção de uma terceira via social-democrata, na medida em que esta se identifica com várias teses do procedimentalismo liberal e da democracia republicana sem, no entanto, reduzir-se a suas versões mais extremas (HOWARD, 1996).

5. Para Habermas, o direito (Recht) é o medium primário de integração social na sociedade moderna. Ao contrário da leitura dualista-funcionalista do direito na Teoria do Agir Comunicativo, Faktizität und Geltung parte da existência fática do direito no seio da sociedade enquanto princípio positivo de coerção para buscar uma justificação discursiva de forma a destranscendentalizar (detranszendentalisiert) o âmbito noumênico de teorias da justiça e evitar o funcionalismo sistêmico da sociologia do direito. O direito é tomado prima facie como poder (Macht), isto é, como instrumento coercitivo de violência (Gewalt), sem, todavia, pressupor a sua legitimidade que deve ser estabelecida pelo consenso de quem se submete ao império da lei no estado de direito (Rechtsstaat, rule of law). Daí a tensão inerente ao sistema de direitos (Rechte) do Estado democrático constitucional moderno: do ponto de vista da autonomia pública, a faticidade do mundo social e dos fatos sociais delimita nossa liberdade de ação (obrigação, coação, enforceability), enquanto a nossa 
autonomia moral procura justificar nossas reivindicações de validade universal. Essa tensão entre faticidade e validade reflete o paradoxo moderno do direito já antecipado pelo princípio kantiano do direito universal, quando buscava as condições que viabilizariam que o livre arbítrio (Willkür) de um indivíduo pudesse se harmonizar com o livre arbítrio de outrem segundo uma lei universal da liberdade (Rechtslehre Einleitung $\int \mathrm{C}$, p. AB 33). Habermas, porém, crê superar a aporia kantiana da autonomia pública definindo-a através de uma rede diferenciada de arranjos comunicativos para a formação discursiva da vontade e opinião pública e de um sistema de direitos individuais fundamentais. A intenção de Habermas é articular a autonomia privada de indivíduos que perseguem seus projetos de felicidade com a autonomia pública que garante o bem comum, idealizado pela vontade geral rousseauniana e pela soberania popular. Neste sentido, o intento de Habermas coincide com o de Rawls na articulação entre a razão pública de inspiração iluminista com a democracia deliberativa republicana. Para Habermas, assim como Rousseau e Kant não lograram articular razão e vontade em termos comunicativos, Rawls se contentou com a distinção entre justiça política e moralidade, as quais permanecem, todavia, no nível da normatividade pura (HABERMAS, 1998, pp. 82ss.). Nos capítulos 3 e 9 de Faktizität und Geltung, Habermas resume a tese central de sua teoria da democracia: a fim de mostrar a relação interna entre o estado de direito (rule of law, Rechtsstaat) e a democracia (democracy, Demokratie), Habermas recorre ao conceito de política deliberativa de forma a garantir a autonomia privada e pública de sujeitos legais dentro do próprio processo democrático de legitimação (HABERMAS, 1998, pp. 427-446). Daí sua apropriação do modelo procedimentalista, privilegiando os pressupostos comunicativos e as condições procedimentais da formação democrática de opinião e de vontade como única fonte de legitimação (HABERMAS, 1998, pp. 452460). Interessantemente, Habermas cita os mesmos autores que Rawls (Frank Michelman e Joshua Cohen), ao introduzir e desenvolver sua concepção procedimentalista de democracia deliberativa como alternativa ao liberalismo e ao republicanismo. Rawls, por sua vez, observa que Habermas, na verdade, distorce a tradição histórica liberal ao classificar Michelman como um comunitarista "republicano cívico" (RAWLS, 1996, pp. 166, 237-339, 396-399, 407-415). Na primeira parte do sétimo 


\section{4}

capítulo de Faktizität und Geltung, Habermas recorre a vários modelos normativos empíricos de democracia, para criticá-los e oferecer sua própria leitura crítica, por exemplo, do que ele chama "democracia deliberativa" em Joshua Cohen. Tal estratégia segue a crítica ao comunitarismo jurídico de Michelman, articulada no final do capítulo 6. Assim, o reexame de "modelos de democracia" (modelos normativos versus modelos empíricos) para enfocar teorias realistas da democracia e embasar sua teoria discursiva da democracia radical, segue o reexame prévio dos modelos liberais, republicanos e procedimentais quanto ao papel da Suprema Corte e à concepção do constitucionalismo americano (HABERMAS, 1998, pp. 267 ss.). Esta seção reflete, de resto, as investigações elaboradas por Habermas numa conferência na Universidad de Valencia (Espanha) em outubro de 1991, onde contrapõe o modelo republicano ao liberal segundo suas respectivas concepções de cidadania, direito e natureza do processo jurídico (HABERMAS, 1994). A teoria discursiva, segundo Habermas, associa ao processo democrático conotações normativas mais fortes que o modelo liberal e mais fracas que o republicano, evitando que a política deliberativa dependa de uma cidadania coletivamente capaz de ação mas de uma institucionalização dos procedimentos correspondentes. Assim como o todo social não deve centrar-se no Estado, enquanto macro-sujeito que se propõe um fim ou bem comum, tampouco se concentra num sistema de normas constitucionais que regulem de maneira inconsciente, mais ou menos automática, o equilíbrio de poder e o compromisso de interesses conforme o modelo do tráfico mercantil. $O$ modelo procedimental da teoria do discurso, segundo Habermas, concebe, ao contrário, a intersubjetividade de ordem superior que representa processos de entendimento mútuo (Verständigung) que se efetuam na forma institucionalizada de deliberações nas corporações parlamentares ou na rede de comunicação dos espaços públicos políticos. Como Jean Cohen e Andrew Arato observaram, tais espaços consolidam o próprio tecido social da sociedade civil, que pode ser contrastada com os subsistemas do Estado e da economia, diferenciados do mundo da vida moderno, na medida em se especializa na reprodução discursiva e institucionalização de tradições, solidariedades e identidades (COHEN \& ARATO, 1992, pp. 429, 434ss.). Assim como no modelo liberal, Habermas enfatiza o respeito dos limites entre o Estado e 
a sociedade, mas acrescenta que a sociedade civil se distingue tanto do sistema de ação econômica quanto da administração pública, enquanto base social de espaços públicos autônomos.

6. Embora o termo "democracia deliberativa" tenha sido forjado nos anos 70 por Joseph Bessette para combater interpretações elitistas e aristocráticas da Constituição americana, foi somente nos anos 80 que foi desenvolvido ao lado da crítica ao liberalismo e da reabilitação de concepções participativas da democracia constitucional (em "Deliberative Democracy: The Majority Principle in Republican Government", de 1980) - após, portanto, a recepção da obra-prima de Rawls e subseqüente crítica comunitarista (BOHMAN \& REHG, 1997). Segundo Joshua Cohen, a democracia deliberativa pode ser definida como "uma associação cujos negócios e ocupações [affairs] são governados pela deliberação pública de seus membros" (COHEN, 1989, p. 67). Tanto Cohen quanto Michelman se propuseram a elaborar uma concepção procedimental de política deliberativa, de forma a estabelecer critérios normativos para o ideal de escolha racional e decisão coletiva, viabilizando a institucionalização de práticas que promovam o bem comum numa democracia constitucional. Cohen elucida o conceito de uma política deliberativa (deliberative politics, deliberativer Politik) por intermédio de um procedimento ideal de deliberação e de tomada de decisão (einer ideale Prozedur der Beratung und Beschlu,fassung) que deveria ser "refletido" nas instituições sociais, tanto quanto possível. Segundo Habermas, Cohen parte da idéia de uma sociedade deliberativamente regida como um todo e, assim, politicamente constituída, que se encontra plenamente realizada em sua estrutura sociopolítica. Habermas cita Cohen:

"A noção de uma democracia deliberativa enraíza-se no ideal intuitivo de uma associação democrática em que a justificação dos termos e das condições de associação procede de argumentos e do raciocínio (reasoning) públicos entre cidadãos iguais. Cidadãos que em tal ordem compartilham um compromisso (commitment) com a solução dos problemas de escolha coletiva através do raciocínio público e que consideram legítimas suas instituições básicas na medida em que elas estabelecem o referencial (framework) para a livre deliberação pública" (HABERMAS, 1998, p. 305; COHEN, 1989, p. 21) 
Habermas reconhece que Cohen caracteriza de forma plausível o procedimento (Verfahren) deliberativo através de postulados argumentativos, inclusivos, públicos, livres de coerção externa e interna, visando um acordo racionalmente motivado, que pode ser corrigido, reformulado, à luz de interesses diferenciados e que, em última instância, "o procedimento ideal de deliberação e de tomada de decisão pressupõe uma associação que concorde em regulamentar imparcialmente as condições de seu viver em comum, de sua vida comum" (HABERMAS, 1998, p. 306). Diferentemente de Cohen, porém, Habermas sugere o procedimento (Prozedur) do qual decisões procedimentalmente corretas (verfahrenskonform) retiram sua legitimidade. Este procedimento Habermas se propõe a especificar como estrutura central de um sistema político constitucional diferenciado (rechtsstaatlich verfaßten politischen Systems), e não como um modelo para todas as instituições sociais (e nem mesmo para instituições governamentais). Trata-se de evitar, por um lado, a concepção liberal de deliberação procedimental de Rawls e Cohen, e por outro lado, o que seria uma concepção republicana, erroneamente reduzida a um tipo de argumentação comunitarista em autores como Michelman. Com efeito, de acordo com Michelman, haveria um perigo inerente ao próprio ideal normativo da política deliberativa quanto às idealizações juridificantes do seu republicanismo cívico:

"A idéia republicana de jurisgênesis política (political jurisgenesis) pressupõe portanto (no que pode ser chamado de um momento transcendental do pensamento constitucional republicano) que um tal repertório de material normativamente efetivo - publicamente reconhecível, recordado persuasivamente e contestável - esteja desde sempre disponível” (MICHELMAN, 1988, p. 1514).

Para Habermas, se a política deliberativa devesse abranger (aufspreizen), outrossim, uma estrutura de conformação da totalidade social, o modo discursivo de associação esperado no sistema jurídico teria então que se expandir em uma auto-organização da sociedade e penetrar a complexidade dessa última como um todo, o que seria simplesmente impossível em contextos que não podem ser regulados pelo sistema. A juridificação não poderia ser uma tecnicização totalizante pelo fato mesmo de ter de recorrer à razão e ao agir comunicativos imbricados em práticas e vivên- 
cias do mundo da vida, inclusive na interação de processos decisórios de procedimentos deliberativos e de processos informais da esfera pública, no chamado "público fraco" (weak public) da opinião pública. A própria fluidez e complexidade de interrelações culturais e valorativas, tão características das formas multiculturais do mundo da vida, deveriam ser capazes de impedir que tal "juridificação" reificante completasse um processo sistêmico de autopoiesis. Segundo Habermas, o termo Verrechtlichung, originalmente introduzido por Otto Kirchheimer na República de Weimar, referia-se à tendência que se observara nas sociedades modernas a um aumento do direito formal (positivo ou escrito) (HABERMAS, 1987, p. 357). A juridificação que caracteriza a colonização subsistêmica da Lebenswelt pode, no entanto, ser retomada em termos positivos de forma a estabelecer a correlação entre uma teoria discursiva do estado de direito com uma teoria radical da democracia liberal: o estado de direito (Rechtsstaat, rule of law) só se realiza na medida em que viabiliza uma democracia radical (radikale Demokratie), emancipatória, participativa e deliberativa (HABERMAS, 1998, p.13). Desde uma perspectiva cosmopolita e transnacional da mundialização, seria possível resgatar uma concepção normativa da juridificação, por exemplo, no patriotismo constitucional (Verfassungspatriotismus) que assegura a diversidade e a integridade de diferentes formas de vida coexistindo numa sociedade multicultural, em pleno acordo com a constitucionalização do estado de direito (Verrechtsstaatlichung) (HABERMAS, 1987, p. 359). A inserção dos dois apêndices no final de Faktizität und Geltung sobre a soberania popular enquanto procedimento deliberativo e sobre a cidadania pós-nacional num mundo cada vez mais globalizado traduz a preocupação de Habermas com relação a uma possível demonização da juridificação no século XXI (HABERMAS, 1998, pp. 463490; 491-569). O direito enquanto poder legítimo (coação ou violência institucionalizadas) não pode ser plenamente legitimado sem recurso a uma normatividade contrafatual (consensual) embasada num agir comunicativo e numa razão comunicativa. Assim como a própria globalização não deveria ser reduzida a um estado patológico do capitalismo tardio nem prestar-se a reformulações de um misticismo semântico (por exemplo, como se o francês mondialisation fosse mais "politicamente correto" do que o imperialismo cultural da globalization anglo-americana), a 
questão da juridificação não poderia ser de todo abandonada em face dos desafios sistêmicos da bioética, da ecologia, da biotecnologia e da biopolítica em nossos dias. A modernização, compreendida desde uma perspectiva hermenêutico-deliberativa integrando mundos da vida e as diferenciações subsistêmicas de sociedades cada vez mais complexas, viabiliza destarte a emergência de uma verdadeira correlação entre a democratização, a juridificação e a mundialização, assim como entre um Wissenssystem (por exemplo, como o encontramos num sistema jurídico) e um Handlungssystem (num sistema de práticas e direitos exercidos) e entre os direitos fundamentais da autonomia privada (Menschenrechte) e da autonomia pública (Volkssouveränität). Embora não seja esta a sua característica mais radical, permanece decerto o problema de averiguar se a concepção habermasiana de uma democracia deliberativa lograria efetivamente superar a impossibilidade do consenso, sem terminar sucumbindo apenas à regra da maioria, como em outros modelos de democracia convencional.

\section{Referências bibliográficas}

BAYNES, K. 1992. The Normative Grounds of Social Criticism: Kant, Rawls, Habermas. Albany: SUNY Press.

BOBBIO, N. 2000. Teoria Geral da Política: A Filosofia Politica e as Lições dos Clássicos. São Paulo: Campus.

BOHMAN, J. \& REHG, W. 1997. Deliberative Democracy: Essays on Reason and Politics. Boston: MIT Press.

BRAUDEL, F. 1949. La Méditerranée et le monde méditerranéen à l'époque de Philippe II. Paris: Armand Colin.

COHEN, J. 1989. "Deliberation and Democratic Legitimacy", in Alan Hamlin \& Philip Pettit (orgs.), The Good Polity: Normative Analysis of the State. Oxford: Basil Blackwell, pp.17-34.

COHEN, J. \& ARATO, A. 1992. Civil Society and Political Theory. Cambridge, Mass.: MIT Press. 
DRYZEK, J. 2000. Deliberative Democracy and Beyond. New York: Oxford University Press.

FISHKIN, J. 1991. Democracy and Deliberation: New Directions for Democratic Reforms. New Haven:Yale University Press.

FLICKINGER, H.-G. 2006. "Im Namen der Freiheit. Über die Instrumentalisierbarkeit der Menschenrechte”, Deutsche Zeitschrift für Philosophie 54/6, pp. 841-852.

HABERMAS, J. 1984. The Theory of Communicative Action I: Reason and the Rationalization of Society. Boston: Beacon Press.

.1987a. The Theory of Communicative Action II: Lifeworld and System. Boston: Beacon Press. . 1987b. The Philosophical Discourse of Modernity. Boston: MIT Press. . 1989. "Para o uso pragmático, ético e moral da razão prática", trad. Márcio Suzuki, Estudos Avançados USP 3/7, pp. 4-19. 1994. Tres modelos de democracia: Sobre el concepto de una política deliberativa. Madrid: Episteme. Em inglês, "Three Normative Models of Democracy", in Seyla Benhabib (org.), Democracy and Difference: Contesting the Boundaries of the Political. Princeton: Princeton University Press, 1996, pp. 22-30.

1998. Between Facts and Norms: Contributions to a Discourse Theory of Law and Democracy. Trans. W. Rehg. Cambridge, MA: MIT Press. . 1999. "As objecções de Hegel a Kant também se aplicam à ética do discurso?" In Comentários à ética do discurso. Lisboa: Instituto Piaget, pp. 13-31.

2001. The Postnational Constellation. Trans. Max Pensky.

Cambridge, MA: MIT Press. .2008. Between Naturalism and Religion: Philosophical Essays. London: Polity Press.

HELD, D. 1995. Democracy and the Global Order: From the Modern State to Cosmopolitan Governance. Cambridge:Polity Press. 
HERRERO, J. 2000. "Ética do Discurso”. In: M.A. Oliveira (org.), Correntes fundamentais da ética contemporânea. Petrópolis:Vozes, pp. 163-192.

HONNETH, A. 2007. Reification: A Recognition-Theoretical View. Oxford University Press.

HORSTER, D. 2001. Jürgen Habermas zur Einführing. Hamburg: Junius. HOWARD, D. 1996. "Law and Political Culture", Cardozo Law Review 17/4-5, pp. 1391-1429.

MICHELMAN, F. 1988. "Law's Republic", The Yale Law Journal, vol. 97, nº 8, pp. 1493-1537.

OLIVEIRA, N. 2006. " $Z u$ einer hermeneutischen Begründung der Menschenrechte”, Deutsche Zeitschrift für Philosophie 54/6, pp. 829-840. . 2007. "Rawls's Normative Conception of the Person:A Kantian Reinterpretation”. Veritas 52/1, pp. 171-183. .2008. "Husserl, Heidegger, and the task of a phenomenology of justice".Veritas 53/1, pp.123-144.

PINZANI, A. 2008. Jürgen Habermas. München: Beck.

ROSENAU, J. 2002. Governance in a new global order, in D. Held \& A. McGrew (orgs.) Governing Globalization. Cambridge: Polity Press, pp. 70-86.

RAWLS, J. 1971. A Theory of Justice. Cambridge, Mass.: Harvard University Press. 1996. Political Liberalism. New York: Columbia University Press. 1999. The Law of Peoples. Cambridge, Mass.: Harvard University Press.

RICOEUR, P. 1992. Le soi-même comme un autre. Paris: P.U.F.

SANDEL, M. 1982. Liberalism and the Limits of Justice. Cambridge, Mass.: Harvard University Press. 
STEINBOCK, A. 1996. Home and Beyond: Generative Phenomenology after Husserl. Evanston, Ill.: Northwestern University Press.

STIGLITZ, J. 2002. Globalization and its discontents. New York: Penguin.

WALLERSTEIN, I. 1979. The Modern World-System. New York:

Academic Press.

WELTON, D. 2000. The Other Husserl: The Horizons of Transcendental Phenomenology. Bloomington: Indiana University Press.

doispontos, Curitiba, São Carlos, vol. 5, n. 2, p.49-71, outubro, 2008 